\title{
CONTRIBUTIONS OF MUSLIM WOMEN IN EDUCATION
}

\section{Iqra Khan}

Research Scholar,

Jinah University for Women, Karachi

Sindh, Pakistan

Email: iqrak6465@gmail.com

\section{Maryam Bibi}

Assistant Professor, Jinah University for Women, Karachi

Sindh, Pakistan

Email: maryam.shah5@gmail.com

\section{Muhammad Amin}

Professor,

Email: momin.alamin62@gmail.com

\begin{abstract}
The term education has been the living phenomena among the social and cultural lives of the human body that derives the crucial needs and necessities of the modern world. This could be considered as the realistic approach to say-as education provided the positive barrier between the old and new learnings to help bring out the development in the logical and literal minds. The fundamental requirements of education result the possibility when its acquirements are made reachable to the deserving hands. Education is hence freed from all the discrimination and racial comments- welcomes the technological and scientific learnings to those who seeks for it. As, for men, education has been the revolving agenda to succeed in the rushing world and as it's similar for the women of every religion and culture. With the rising inventions and prominent technological factors, the demanding scope for the educational promotions established the future needs. This need in an outcome prevailed the exceeding desires of women to work side by side with men and to meet the necessities of the coming age. The patterned structures that the society follows, advances the efforts of men rather than women and if it belongs to any religion, Muslim women are the first to face the discriminative attitudes in the work places and learning institutes. But to count their efforts in an extensive manner, there are many of the Muslim women who took charge in the advancement of the technological and the social sciences. This article aims at the perpetual challenges and contributions of Muslim women in their respective work areas. The problems and hurdles they experienced at the social and cultural
\end{abstract}


surroundings. The main objective of this paper is to highlight the difficulties and hardships of Muslim women all around the world and the challenging atmospheres they worked in while giving their utmost for the betterment of society.

\section{KEYWORDS}

Muslim, Women, Education, Islam

\section{INTRODUCTION}

This is the stereotypical debate against Islam to call it as the narrowest and backward religion that does not favor Muslim women's freedom and liberty but the claims that the world imposes directly misspends and results into no actuality. Even Islam vividly expounded the values of both men and women with the suitable patterns of laws and regulations to act over it for the smooth survival in the society. The religion Islam deliberately discusses the rights for both men and women and among these rights are the freedom it gave to women in acquiring knowledge and education.

The contemporary Muslim world struggles to peak at the upper levels of technologies with the challenging atmospheres in the rushing world and as education with the featured modern learnings are important for others have a disseminating effects on the Muslim population too if the advances are not available as per their demands.

The collaborative investments of men in the scientific and technological studies modernized the learning patterns for the present generation that certainly provided the benefitted opportunities for both men and women for the future. The fact that is known to the world is the un educative margins developed in between the people belonging to the strict traditions and cultural standards resulting in the obstruction to the new world's patterns.

This is more than a desolate comment suggested for Muslim women as they are found less educated as compared to the women relating to the other religions. Where women aged between 25 till 34 were found with no good schooling but as in other regions of the world, Muslim women has shown tremendous amount of enrollment in the learning institutes and universities.

In fact, Islam reorganized the living standards of the people where women were given the extreme importance over men, although valuing men as the dominant figures but the significance they held was superior among males. The religion Islam motivated the existence of women as the prestigious part of the society to allocate the completeness at once. And as, with the advancements in their status, Islam emphasized upon their basic and fundamental rights that includes good standard of living and high yet quality education. 
Likewise, to explain the seriousness of the speech, the holy Quran supported the idea of education for all by revealing upon the first Ayah that included the word "Iqra" which means "to recite" - the word appeared initially over Prophet Muhammad (S.A.W) to elaborate the notable subject to the society. The main focus diverted from human rights to the acquirement of education that was bounded for all wither men or women.

The discouraging effect afterwards resulted in the tedious and monotonous society where women were devalued and their rights suspended. The duties that differentiates both men and women at standard level- as men enjoys their authority and are able to withstand or recover quickly from difficult conditions while women are resolute and contended in accepting their challenging tasks to help strengthen their solidarity.

According to the suggestions, Muslim women experienced the high chances of mundane and dull decisions that in a result demotivated their excitements and passion for advanced learnings- and with the economic hindrances and customary limitations, they have encountered the close doors to the modern and technological world. With the coming new scopes, the mindsets of the Muslims are giving spaces for the fashionable patterns of the society. In accordance with the postmodern theories, Islam has been discerned "old fashioned" and "domineering" specifically for the un liberal advancements for females in the fields of education and standard living but Islam is the first and only religion that came up with the principles and ideologies regarding one's independence and right to acquire knowledge. Even Islam emphasized greatly upon the standards of women either Muslim or non- Muslim- to secure their honor and help enhance their efforts in determining their worth to later emerge as an empowering figure in the market area.

The historical discussions marked women unqualified as compared to the one who belonged to the higher classes in times of Mughal period but later after the separation of Muslims and Hindus in a sub-continent, Muslim women appeared as the dominating force for the uplifting of the better society.

As, in the purposeful acquirement of modern education, Muslim women have labeled their involvement in the updated vast fields of business and marketing, fashion industries and office work hold. Contributions made in social science or in medical fields, Muslim women remained at top of the list side by side with their male peer groups and social circles. At time of $11^{\text {th }}$ century- the era of Muslim development, multiple markets engrossed common people's interest most importantly on trade and commerce and gave complete focus on merchandizing- this, however, paved roots for the establishment of Islamic learning centers and institutions to accomplish the academic aim in the Muslim society. 
The contributing essence involves the major hard works from the side of Muslim women who celebrated their significance through working on the learning squares. More deliberately, their collaborative efforts are highlighted majorly in fiqh, literature, mathematics, social sciences and business studies-although, in other different cases, Muslim women experienced unethical societal attitudes under the restrictive surroundings- but the independency with which they were rewarded was fully enjoyed by them in their services either as a civil devotee or as general physician in the war fields without any fear of stereotypical barriers.

The $21^{\text {st }}$ century revolves around the intruding complications in the various different sphere of the globe either scientific, technical or societal. These issues being monotonous in first place are repetitive on the other. Where technological competencies developed the contesting distraction among the disparate groups of religion and social classes, the discriminative functioning among the inconsistent masses developed the categorization between the literate and illiterate.

Moreover, the contradictory ideas paved ways more strongly as with the establishment of technological world. According to the year 2020's calculative margins, the world's population comprised of approx. 7.8 billion people with around $50.4 \%$ of male majority while $49.6 \%$ of the female population. Similarly, $90 \%$ of the male listed literate and $82 \%$ of the women rated educated globally. And so, if to distinguish both genders in regards to their religions- Muslim women rank lower as compared to the other women of different religion.

The introductory discussions elaborate the challenging circumstances of Muslim women in the educational areas. As, this is an alarming situation for the country especially, as the improvement that the society need also comes through their devotions. The typical and traditional exercises promoted the Jirga and Wade rah systems in the different provinces of the world, most particularly in India and Pakistan where girl's education is still considered a burden and a waste for them- their families believes that the acquisition of modern learning may result in the excessive freedom of their child that later develop in them the rebellious features against the society.

Although, the conception above marked have no alleged basis as the history has been marked already with many of the great figures with their remarkable contributions to the society.

\section{RESEARCH OBJECTIVES}

1. To discover the workings of Muslim Women in the field of education.

2. To explore the challenging aspects that leads their lives

3. To differentiate the stereotypical and cultural barriers. 
4. To observe the importance and significance of Muslim women in today's world.

5. To suggest the suitable solutions of the mentioned problems.

\section{RESEARCH QUESTIONS}

1. What are the contributions of Muslim women in the field of education?

Moreover, to investigate the different problems and challenges face by Muslim women in Asian and European world. How multiple factors drives together to construct the strenuous situations in their work that later generates the challenging constituents in the establishment and progress of Muslim women contributions. The important findings in the article focuses on the contrasting aspects and ideologies regarding Muslim women's progress and devotion towards the establishment of educational strand.

\section{RESEARCH METHODOLOGY}

The prevailing analysis is the type qualitative research- based on the secondary data that is gathered with an account of authorized books, articles, magazines, reports and different periodicals to support the qualitative workings of the article. The main issues regarding Muslim women contributions have been collated through the possibility of different cooperative suggestions and opinions that are later sequenced into the distributive manner to shape the reasoning discussion with the favorable clues and supportive ideas. The concerned study is standardized and definitive in orderdemonstrated with the formalized pattern of the research techniques.

\section{DISCUSSIONS}

\section{Status of women in Islam:}

"O mankind, surely We have created you from a male and a female, and made you nations and tribes, that you may know each other. Surely the noblest of you with Allah is the most righteous. Surely Allah Knowing, Aware." (Holy Qur'an, 49:13).

Islam declared the status of women as the significant to the society and messages its followers to believe in their honor and protect their rights and values. Prophet Muhammad (Sallahu Allaihi wa sallam) in his farewell sermon, notified Muslims about the concerning issues regarding women and said, "Observe your duty to Allah in respect to the women, and treat them well." The religion Islam elevated the standards by saying, "O Prophet! Tell your wives and your daughters and the women of the believers that they should cast their outer garments over them (when abroad); this is more proper, that they should be known (recognized as such) and not molested. And Allah is ever Forgiving, Merciful." (Holy Qur'an, 33:59). More importantly, the first message appeared to Muslims was to acquire knowledge that was obligated for both men and women. 
Although, this is the misconception of believing in Islam as an unsophisticated and ignorant religion that suppresses the freedom of women and their rights- the factual evidences are found in Holy Quran that develops the defensible weight in the fundamental and informative assists to the world. The arguments raised by the people have been misleading the veraciousness; Muslims and the religion possess as being the follower and frames it as the oppressive one. but as in Islam it is rightly said: "And one of His signs is that He created for you mates from among yourselves that you may dwell in tranquility with them, and He put between you love and compassion; most surely there are signs for a people who reflect."(Holy Qur'an, 30:21)

However, the duties and responsibilities of the women have been clearly declared with an announcing reward from the Almighty in different shapes and situations. Even, in the Holy Quran, women have been given honor and support through 'Nikah' that is obligatory and official to the married one. In a much greater sense, marriage proved to be the imperial practice among other Holy acts that withheld in it the crucial duties for man, including the protection of their wives' dignity, rights and honor. The teachings of Islam enunciated the ensuing responsibilities of women in the form of marriage, while Prophet Muhammad (Sallahu Allaihe Wassalam) enounced that, "there is no escape from Nikah in Islam". He further summarized that, "Do not get involved in too much prayers that you forget about the duties of your wives, children and yourself." (Bukhari)

In Islam, women, just like men, can have virtues of equal value while this is not so in other religions (Qur'an, AlAhzab(33), 35; At-Tauba(9), 76). However, after the revelation of Holy messages over Prophet Muhammad (P.B.U.H), Islam formalized the fundamental principles for both men and women and declared their authorities with the division in their duties and responsibilities. As, men were appraised as the masters to the women while women were privileged with honor, dignity and glory with the right of complete freedom to judge and make decision. The true depiction of both men and women in Islam is pure and dedicated towards each other with an aim to achieve faith and spirit through obeying the sayings of Almighty Allah and respecting the status mentioned for them.

\section{Status of women in the modern world:}

Women all across the world has been judged differently as compared to the working class of the male majorities. Although, their duties and commitments differ from each other but in the today's modern globe, both man and woman are being treated not exactly the same but, in some majors, women have taken charge over man in different modes of work.

The modernization of the $21^{\text {st }}$ century lead to the discoveries of the generational 
necessities but bought with it the racial and discriminative aspects among the people of the world. Women, in specified work areas have been questioned about their qualities and their qualification. Before the pre- developmental influences, women were put into the limelight of the public opinions and were restricted under the traditional and normative ruling.

A traditional man, as from the beginning is the headman of the family with the suitable merits to direct his authorities while women with the unconfirmed rational kept out of scope. But on the contrary, the positive setups are although experienced in the progressive manner where in many of the houses, women have been permitted the allowable approaches to overlook the certain matters of the society.

The struggling background of the women highlighted the historical debates of both $19^{\text {th }}$ and $20^{\text {st }}$ century, when women realized the importance of getting education, participating in politics and social movements. They represented the ideologies to the required platforms for women where they can raise their expressions towards any normative, governmental and societal phenomenon.

Even in the Muslim countries, the problematic situations are on verge to clear out the difficulties of women that it is considered as racial and against their liberal rights. As, in Saudi Arabia, conference took place to put light over the intricate complications they faced where both men and women participated to argue over. The purpose to gather this meeting was to put in discussion the issues regarding women as they were unsatisfied with the system of traditional controlling and restrictions they suffered while in achieving their rights for freedom to say and act.

Although in the perpetual circumstances of modernity and establishments in technology and social sciences, women have developed the platform to convey their voices to the required authorities. In political campaigns, social movements, educational sites or in scientific means, women either Muslim or Non-Muslim have been involved in their concerned areas of interest. We see women even in Hijab today as a doctor, engineer and a parliament member. Their reach now isn't been restricted to their kitchens but they have become the requirement to the society- their dignity and standard is, however, been secured through different law sanctions but the factual issue remains domineering and overflowing throughout the debate without any measures to decide.

\section{Muslim women and their contributions}

The developmental effects of the technological world have been influencing people of different groups with the difference in thoughts and mindsets. In the postmodern era, people are judged according to their qualifications and the achievements they made for 
the world rather than on the perceived ideology of being targeted with the physical appearances, followers of different religions or relating to the different cultures or languages. The aim that education provide within was to educate the distinctive ideas of the human mind, to reject racial discrimination and to prove the world with simple and formative judgement that shall be made according to their progresses.

In addition to, the progressive majors took under the efforts of struggling backgrounds that Western borders, people are discerned strictly. According to their mental setup, they think of Muslim women as covered under Hijab and have been terminated from all of their rights due to their religion- People of Western, typically are concerned with the ideology about Muslim women that they are restricted under the merciless ruling of their parents and husbands where they're wonder stricken due to their cultural and traditional barriers.

In the book, The Representation of Muslim Women in Renaissance England the position of Muslim has been mentioned as in those times, Europeans and English writers were highly impressed by the modesty and life-style of the Muslim women of the Ottoman Empire. They observed the major differences between Muslim and Christian women. Comparatively, Muslim women were more deliberately engaged in the obedience of their husbands and were more obliged to their commands and honor while on the other hand, Christian ladies were more on to the side of getting liberal aesthete and demanded more independence from their husbands.

Moreover, in times of the early Islamic era, Muslim women were ill-treated, some being buried alive while others devoid of their basic needs. Islam with it, bought the revolutionary theology for the mankind where women conquered their significances and importance as the liberal individual in the society. As, Islam elevates their diligent efforts as the member of the society- promoted their works as an example to the world. Their involvement in trade and economy, war and medicine has been picturized in the history of Islam.

\section{Contribution of Muslim women in business}

Although, in those backward situations of enforced cultural patrimony, the strongest of the women empowerment has been bestowed over the supremacy of the male dominancy at the times. Hazrat Khadija (R.A), wife of Prophet Muhammad (S.A.W) and the first Muslim businesswomen in the Islamic History made crucial highlights in the period of "Jahiliya". The Holy figure exampled as a master in trade and economicssingle-handedly flourished her business all across the Arabian Sahara.

Furthermore, the contributive working of Muslim figures greatly influenced the societal patterns of every century where their engagements in social and civil works 
positively UN burden the responsibilities over male majorities. However, they, through their involvements in the trade and commerce diverted the focus not only on of their duties as a house wife but as an empowered and compassionate woman. This in a result approved the stability in the financial support to the society where the workloads were divided as per their capabilities.

In the land of Nigeria, Muslim women's efforts as an entrepreneur and as a trade settler have the huge influence over their economy. Cities, like Kano, Katsina and Zaria have large masses of married women as the money earners. The businesses have been controlled from their houses to help maintain their morality and righteousness.

As in a support to women's association to trade, Prophet Muhammad (PBUH) declared, "Sustenance consists of ten parts: nine in trade and one in other belonging" (Al-Ghazali, n.d).

While in Islam, showing willingness towards business is observed as a qualified act from the believer towards the Almighty. Moreover, the status of businesswomen has been standardized to be as the success for the society and the coming generation. "Righteous businessmen will be the first to enter paradise", and "A truthful merchant will be raised on the Day of Judgment together with the truthful and the martyrs." Prophet (PBUH). However, the concerned guidelines regarding Muslim women's business has been mentioned clearly in the religion- with the two major determinations. First to ask for husband's consent regarding job and business settlement and second to avoid the type of work that results in a family disorganization.

\section{Contribution of Muslim women in education:}

The development of competitive impacts from the corners of the European states has been evolving anxious institutions of challenging and suffocative atmospheres towards the impression of Islam and Muslims- And, as, the historical perspective regarding them as a citizen of the nation has been trending issue with the picturization of their true self. However, Muslims aren't completely disallowed to rank their status but the irreconcilable businesses interpret Muslims into two divisions- one being honest, earthly and profane while others as reformist, fanatic and outrageous- in short, the insecure figures to the society.

As, after the 9/11 crisis, Muslim world encountered the un numerable complexities including Islamophobia comments and racial discrimination towards the Muslim. At the same time, Muslim woman suffered exactly the same as Muslim men. The confusing state of affairs continued as for a long time being, when multiple restrictions happened till the least surviving states. Muslim women were banned of the veil and hijab, molested publicly and were harassed openly in the institutions where they 
studied and taught.

Furthermore, not only in United States and other neighboring countries did Muslims confronted the venomous attitudes but in France, Germany, China and many other countries put forwarded the unethical grounds for Muslims either men or woman. Islam gained infamous disputations in the form of repellent and unpleasant standpoints that referred the Muslim population as per their race, ethnicity and culture.

Meanwhile, in the hypercritical situations, the astounding contributions contracted the additional progressive attainments with the advanced reconciliation with the modern world. The ancient historical background revises the marvels of the Muslim aura- their intimacy towards literature, trade and education; despite of the traditional barriers, the enjoyment of the ambience in the Muslim women's persona excited way more than the world think of.

The establishing motives of Muslim women's contributions excelled as from the centuries. As, the first and oldest library was inaugurated by Fatima Al-Fihri in Morocco, later it was reinstated by the Canadian-Moroccan architect Aziza Chaouni. This library comprises of 4000 ancient books with many other Arabic manuscripts.

To further elaborate the aspiring workings of Muslim women, Hazrat Ayesha (R.A), wife of the last Messenger (PBUH), gathered and narrated the important sayings and messages of Prophet Muhammad (PBUH) into the book form- later taught people under the light of the Islamic primacy. She is considered as one of the qualified Muslim women to deliver her performances as a preacher of Islam and actively served as a scholar, political and social activist among the other valued Sahaba Ikram (companions of Prophet PBUH).

However, the typical mindsets meet restrictive boundaries, women at the times of Jahiliya possessed no great status among the male population- they were considered a burden and misfortune to their families. Amid the transfer of attentive energies from the side of the society, Islam disregarded the pessimistic approaches of the masses and opened the wide gate for the enactment of the services by Muslim women to participate even in the expensive work fields.

Therefore, the empowering stands in the premature era involves the significant accounts of efforts. One of those includes, Khawlah bint al-Azwar's engagements in the war field that has been the crucial talk today. Side by side with other warriors, she displayed the different and positive side of Islam through her uncountable struggles. Lubna of Cordoba, the inspiring mathematician, poetess, writer and grammar expert of the times, lead the authority over the library consisted of more than 500,000 books. 
The medieval epoch reminisces the early contributions of Muslim women who broke typical mindsets of the present society. This, at the beginning of the era, brought laborious ventures in the form of inferior substandard placements and unwelcoming attitudes towards them at the initial stages. However, the prevailing circumstances of the present age reflects the same unfortunate affairs. Muslims as in the contemporary and challenging globe, surrounded within to face Trump's stratagem- relatively predicted into the strenuous state. Most importantly, people all around the world, especially Muslim population have been confronted with the pushed over ordinanceslater, instigated them into the numerous episodes of appalling events at the International level.

After Christianity, Islam ranks second as the most influential and practicing religion in France with the approximation of five million Muslims living in as its citizens. The modifying reformation of Muslim women refers now to be a corner stone in the socialized and structured societal fields. The differences that their lifestyle, matters crucial and flourishing with adequate margins. The chief module of the resisting changes in their current status includes multiple different promotional ideologies. Their involvement in the political affairs chances to expand the active participation in the social setups- to maturate the current issues of Muslim women in regards to the educational autarchy, religious sovereignty and public prepotency as the citizen of the country.

The primitive debate over the contributing efforts in the times of Golden period marked the Muslim history culturally strong with the aspiring production of assessments in the institutional and communal composition. The extraordinary adaption geared up their enticing portfolios with their geniuses. In order to execute the purposive momentum over the existential crisis, Muslim women delegated to the certainty of the approved institutional rights- to observe and seek education under the legalized set standards.

The formalization of educational necessities and social redeem came into progress after the establishment of Madrasa, learning centers and libraries in the different regions of the Muslims and Non-Muslim's states. The world's oldest existing university of the times is that found in Cairo- Al-Azhar University, the religious learning arena build specifically for Muslim women to pursue future requisites.

Mohammad Akram Nadwi, the religious scholar, assembled the collective efforts of Muslim women scholars in the Islamic history through the different sequential biographic dictionaries. Meanwhile, in his experimenting phase, he concluded, "I thought I'd find maybe 20 or 30 women," until he published 40 volumes of his dictionary with 8000 of his findings. His initial conclusive work includes the discussion of a female scholar- born as a native of Baghdad, reminiscing the $10^{\text {th }}$ 
century aura with her travel series to Syria and Egypt in order to teach women as a Mohaddes. Continuing the cognitive acknowledgement of their practices, another scholar from $15^{\text {th }}$ century, enkindled the set approaches of learning sessions of Hadith to the male students outside of Prophet Muhammad (SAW) grave.

The unraveling present period of inventions and technological functioning, together with the correlative empathy framing the accuracy of the accelerative forces between the discriminative and ethical delusions. Amazement to the fashionable world, Muslim women has maintained their leadership under the supervision to their particular acknowledged practices. They have become the influential part to the neoteric society either in the social or civil activities. Muslim women as an activist, political leaders or social counselors, put in efforts to manufacture the propitious platform in releasing out the societal tensions coming right after from the typical minds- to help secure the sophisticated outcomes for the balanced functioning of the women's rightful salvation and liberation.

However, through multifarious encumbrances among the social grouping against Muslim women in many working areas- they emerged with the substantial and generous impression to the society. Amani Al-Khatahtbeh is the prominent leading figure in the founding the Muslim media channel to formalize the term "Muslim". Along with the cooperative association with the media management, she organized "Muslim women day" to narrate the true self of Islam and Muslim women.

While, on the other hand, Dalia Mogahed- an Egyptian and 1975 born, is leading member of the World Economic Forum's Global Agenda Council on the Arab World and the founding research director of Institute for Social Policy and Understanding to instigate the escalated modules of the modernized controversies developed against Islam.

Relating to the educational background, Su'ad Khabeer- the professor of American Culture and Arab and Muslim American Studies at the University of Michigan and an eminent researcher whose work illustrates the crossing ideology of United States in an observing customary and discriminative disparity.

To the present date, the important feature in the Islamic history remarks the endeavors of Muslim scientists either in scientific or medicinal outlook. Al-Khwarizmi- the mathematical master, Ibn AL Haytham- the physical law proponent and Ibn Sina- the medicinal proficient are the supervisors to the modern studies. Not very few but highlighted competitive masses in the composition of the respective fields grew well and updated in the medicine, social sciences and philosophy. 
The increment in the educational setups, hoisted the positive side of Islam in front of the Western world respectively in the different modes of the working areas. The primordial Islamic learnings eliminated the synchronic prejudice of the general public by safeguarding the significant ideologies of the Muslim population.

To concentrate emphasize over the efforts of Muslim women, another virtuous figure shaped updates in the institutional corners. The prominent writer, lecturer and an entitled personality of the times, Fatima-bint-Muhammad prepared authentic lectures on Sahih Al- Bukhari, whom she later taught them to her immense crowd. She is awarded with a name "Musnida Asfahan" by the people of that times. The authorized management of the era, deliberated the voluminous records in many of the written versions. Umm al-Khayr Amat al-Khaliq, however, is considered as the last scholar of the Holy Ahadis of Hijaz.

The Islamic hisory is certainly an indicative and representative in regards of annunciating women ingeniousness and sagacity in accordance with the impartment of the designated charges in the particularized fields and scopes. The prominent Muslim lady of Islam- more dominantly known to be the first elected market assessor by Umar bin ibn- al- Khattab to honor her civil services to the people. Distinctive in nature, Aisha bint Muhammad ibn Abdul Hadi, born with the leading attributes of professional mindset- was the mentor and guide to the male students of the institutional forums of Damascus.

The restoration of the academic backgrounds in the Arabian borders elevated higher among the different classes of the female majorities. Their main focus matured in the institutional learnings, most probably, based on Hadis, Fiqh, Law and academic disciplines with the developmental and enlightened consequences.

The 'Pride of Women', Zainab bint Kamal- set examples of decency with her splendors in delivering lectures to her students on more than 400 Hadis books. In that current era, her balanced and positive temper towards her pupils, impressed many of the common people.

The regulating law and order phenomena of the concurrent world processes according to its patterned societal and cultural structures- as man with the sheer authorities and mandate. But in contrast to the earliest Muslim history, side by side with men worked Muslim women, who readily accepted the stereotypical stances of the society- to help graduate the irrefutable beneficence to the world.

The first ruler lady to overlook monarchy was Arwa al-Sulayhi- belonging to Yemen and adopted by her uncle after the death of her parents. Later, became Queen to the 
royal prince of the times whose illness led her to hold powers. Her services as a female leader focused majorly on the social services for the nation. Her involvement arises most commonly in educational and civil settlement. As, her according to her plans, she established institutes, masjids and other public sector services.

Sutayta al-Mahamili, student and expert in mathematics, was an inspirational figure of the $10^{\text {th }}$ century- who, with her intuition and genius gave credible equational solutions. Moreover, her satisfactory efforts mainly lie in the Arabic literature, law and Hadis. The pronounced Muslim women throughout the time duration of $11^{\text {th }}$ century was Wallada bint al- Mustakfi- a celebrated figure, well-known for her mastery in poetics and oratory. She founded a learning institute for females where she free poetry classes. The historical compilation and encyclopedia of the Islamic corners, references the governing influences by the sides of Muslim females- with their descriptions of an adequate and compelling features.

Hafsa ar- Rakuniya was the teacher of Wallada, who taught her with the cultural and ethical lectures. Originally, a poetess, a dynamic one- who loved to write on love poetry with the essence of detailed love scenarios. The other mentions in Islamic anthology about the significance of female inspiration includes, Mariyah-al-Qibtiyyahresearched Alchemy, Rasa- An Indian writer, who wrote on medicinal discoveries, Zainab al-Ghazali- a person of influence and Umm Warqa bint Harith is among those pioneers who served in battlefields and compiled the Holy Book Quran.

Apart from the explicative debate over the Arabian contributors, Pakistan- the culturally rich quarter covers the absolute placement under the argumentative discourse. The recounted endeavors sequentially inaugurate just after the name Arfa Karim- the youngest computer scientist and Microsoft certified professional, who at the age of nine, cleared the MCP test and entitled her name as the expert in the field of Technology and sciences.

On the other hand, the Iron lady of Pakistan- Muniba Mazari, is the isnpiration to the inventive world. An Artist, social influencer and wheel chair model. She, through her words and powerful mindset raised positivity among the different nations of the world. Her motivational speeches made her the Pakistan's first female Goodwill Ambassador by the United Nations Entity for Gender Equality and the Empowerment of Women. Dr Nergis Mavalvala, is an astrophysicist who participated in a US collaborative project to find the clues of the gravitational waves.

\section{CONCLUSION \& RECOMMENDATIONS}

From the introductory section till the end of the literature review, we experienced the innumerable contributions of Muslim women under the light of Islamic philosophy. In 
contempt of the disregarded construction of differing psychologies and ethos of the outer world, the imperative achievements made since after the origin of Islam remains enjoyable and aesthetic in the historical backgrounds of Muslim masses.

In conclusion to this qualitative research, the inclusive endeavors of Muslims either male or female requires thorough admittance of social acknowledgement and enlightenment in the global chronologies. As, the analytical approach of the foremost paper, directs the proximate attention of the innovative world towards the issuing dilemma and catastrophes happening with the Muslims and their respective religious and regional associations - it aims to confirm the maintenance of the affirmative shaping of the cultural and social stability of Muslims through the proficient transfer of their acknowledged ideology to the world.

In an addition to, the interpreted statements under the whole review delineates the collaborative efforts of Muslim women and the challenges they endured as the central part of the typical society.

\section{REFERENCES}

Women in Islamic society (2020), retrieved from: http://www.oxfordislamicstudies.com/article/opr/t243/e370

Katherine B. (ed) (2005), Muslim Women Activists in North America: Speaking for Ourselves, University of Texas Press.

Ilhaamie Abdu (2017), Muslim Women Entrepreneurs' Motivation In Smes: A Quantitative Study in Asia Pacific Countries, 7(1), 27-42

Great women in Islamic History: a forgotten legacy (2020), retrieved fom https://funci.org/great-women-in-islamic-history-a-forgotten-legacy/?lang=en

Janet Pérez, Maureen Ihrie (2002), The Feminist Encyclopedia of Spanish Literature: A-M, retrieved from https://books.google.com.pk/books/about/The_Feminist_Encyclopedia_of_Spanish_Li t.html?id=zrlWAAAAYAAJ\&redir_esc=y 